\title{
La Gripe de 1918-1919 y la transformación del ámbito laboral de las profesiones sanitarias en España
}

\section{The 1918-1919 Influenza and the transformation of the workplace for the health professionals in Spain}

\section{María-Isabel Porras-Gallo*}

Resumen: En el marco del renovado protagonismo alcanzado por la pandemia de gripe de 1918-1919 como consecuencia del desarrollo de la COVID-19, se ofrece una reflexión desde la historia social de la medicina de la transformación que la mal llamada gripe española operó en el ámbito laboral de los profesionales sanitarios en España, conjugando lo sucedido en la ciudad de Madrid y en el conjunto del país. Utilizando como fuentes monografías y las principales revistas científico-profesionales de médicos, farmacéuticos y veterinarios, combinadas con una selección de prensa general y documentación de ambas Cámaras Parlamentarias, se muestra cómo la actividad diaria de los médicos estuvo marcada por la intensificación de su labor clínica y un gran despliegue de actividad investigadora en el laboratorio con el fin de fijar la etiología de la gripe y poner a punto medios terapéuticos y profilácticos específicos. Se muestran las dificultades encontradas en dicha tarea y el interés de farmacéuticos y veterinarios por reproducir esta nueva faceta científica y competir con los médicos para lograr una mejor instalación social en la lucha contra las enfermedades infecciosas desde la Bacteriología. EI trabajo pone de relieve igualmente cómo, ante las dificultades para controlar la pandemia, una parte del colectivo médico volvió la mirada hacia las desigualdades socioeconómicas (malas condiciones de vivienda y de trabajo, el hacinamiento, la escasez y carestía de alimentos, medicamentos y productos de primera necesidad) de la población trabajadora y las carencias sanitarias para explicar su gran gravedad, y propuso medidas científico-sanitarias y generales para corregir la situación en el futuro.

Palabras Clave: gripe de 1918-1919; profesiones sanitarias; España.

* Doctora en Medicina y Cirurgia (Área de Historia de la Ciencia) por la Universidad Complutense de Madrid (UCM). Catedrática de Historia de la Ciencia de la Facultad de Medicina de Ciudad Real. Universidad de Castilla-La Mancha (UCLM), España. Directora del Grupo de Investigación Salud, Historia y Sociedad (SALHISOC) de la Universidad de Castilla-La Mancha. ORCID: http://orcid.org/0000-0003-2277-6179. E-mail: mariaisabel.porras@uclm.es. 
Abstract: In the context of renewed interest in the 1918-1919 flu pandemic as a result of the development of COVID-19, this paper presents a reflection from the point of view of the social history of medicine on the transformation that the erroneously named "Spanish flu" brought to the working environment of health professionals in Spain, combining what happened in Madrid and in the country as a whole. Using as our sources monographs and the principal professional scientific journals of physicians, pharmacists and veterinarians, together with a selection from the general press and documentation from both houses of Parliament, we show how the daily activity of doctors was marked by the escalation of their clinical work as well as a considerable deployment of laboratory research in order to establish the aetiology of the flu and to prepare specific therapeutic and prophylactic measures. We show the difficulties this work encountered, and the interest of pharmacists and veterinarians in reproducing this new aspect of science and competing with doctors to achieve greater involvement in the bacteriological fight against infectious diseases. The paper also points out how, faced by the difficulty of controlling the pandemic, a section of the medical profession turned to the socioeconomic inequalities (poor working and living conditions, overcrowding, shortage and cost of food, medicine and basic necessities) in the working population and shortcomings in health care to explain its extreme seriousness, and proposed scientific medical and general measures to correct the situation in the future.

Keywords: 1918-1919 influenza; health professionals; Spain.

\section{Introducción}

$H^{\csc }$ ACE POCO MÁS DE CIEN AÑos que comenzó la gripe de 1918-1919, considerada la madre de todas las pandemias por Taubenberger y Morens (2006) por cuanto todos los virus A de las posteriores pandemias de gripe derivan del virus de 1918. ${ }^{1}$ El desarrollo de la COVID-19 le ha otorgado una nueva actualidad a esta crisis sanitaria del pasado siglo. Al importante número de publicaciones, exposiciones, seminarios, conferencias, jornadas sobre la mal llamada gripe española, que se generaron con motivo de su centenario, ${ }^{2}$ se están sumando

1 TAUBENBERGER, Jefferey K.; MORENS, David M. 1918 Influenza: the Mother of All Pandemics. Emerging Infectious Diseases, v. 12, n. 1, p. 15-22, jan. 2006.

2 El volumen de publicaciones e iniciativas diversas es muy elevado, pudiéndose encontrar información sobre ello en PORRAS-GALLO, María-Isabel; RAMÍREZ ORTEGA, Mercedes. Los efectos de la pandemia de 1918-19 en la lucha contra la gripe en España: el papel de los cambios de percepción del riesgo y la posterior creación de la OMS (1918-1969). In: FERREIRA, Antero (coord.). A gripe Espanhola de 1918. Guimarães (Portugal): Casa de Sarmento-Centro de Estudos do Património: UMinho, 2020. p. 10-30; PORRAS-GALLO, María-Isabel; DAVIS, Ryan A. Introduction: Emerging perspectives of the Spanish Influenza Pandemic of 1918-1919. In: PORRASGALLO, María-Isabel; DAVIS, Ryan A. (coord.). The Spanish Influenza Pandemic of 1918-1919. Perspectives from the Iberian Peninsula and the Americas. Rochester: University of Rochester Press, 2014. p. 1-20. Entre los últimos libros publicados por periodistas científicos con motivo del centenario de la pandemia, cabe destacar: SPINNEY, Laura. Pale Rider. The Spanish flu of 1918 and how it changed the world. London: Jonathan Cape, 2017. En el ámbito Latinoamericano se han producido igualmente numerosos estudios históricos sobre el impacto de la pandemia en la mayoría de los países que la componen, que se han canalizado como monografías y volúmenes colectivos, pero también como artículos en las principales revistas científicas. 
nuevas aportaciones sobre la mal llamada gripe española realizadas bajo la influencia de las condiciones excepcionales derivadas de la experiencia vivida de la pandemia de la COVID-19. Estos nuevos análisis están siendo canalizados a través de las revistas especializadas de cada uno de los campos científicos (historia, historia de la ciencia, historia de la medicina, demografía histórica, epidemiología, antropología...) de forma individual o como dosieres temáticos, monografías, volúmenes colectivos, pero también en la prensa diaria, en programas y documentales de las principales televisiones, YouTube y redes sociales.

En este contexto y desde la perspectiva de la historia social de la medicina, el objetivo principal de nuestro trabajo es reflexionar sobre la transformación que la gripe de 1918-1919 operó en el ámbito laboral de los profesionales sanitarios en España, conjugando lo sucedido en la ciudad de Madrid y en el conjunto del país. Se evaluará en qué medida la actividad diaria de médicos, farmacéuticos y veterinarios se vio trastocada; hasta qué punto la crisis sanitaria y las condiciones creadas por ella fueron una rémora o constituyeron una oportunidad para su desarrollo como colectivo profesional o para facilitar la institucionalización de nuevos profesionales sanitarios.

Como fuentes principales hemos utilizado las principales revistas españolas científicoprofesionales de médicos, farmacéuticos y veterinarios, boletines del Colegio de Médicos de Madrid, publicaciones y documentación de la Real Academia Nacional de Medicina, las actas de las sesiones del Congreso de los Diputados y del Senado y una selección de la prensa diaria durante el bienio de la pandemia.

\section{Contexto, origen y desarrollo de la pandemia en España}

AUNQUE NO EXISTE TOTAL UNANIMIDAD sobre el origen de la pandemia de gripe de 1918-1919, la historiografía lo ha situado fundamentalmente en China o en los Estados Unidos, habiéndose decantado por este último lugar. Sin embargo, sigue siendo conocida esta crisis sanitaria como la gripe española. Este calificativo mal atribuido está relacionado con la coincidencia del inicio de esta pandemia cuando la Primera Guerra Mundial estaba llegando a su fin. De ahí que, por razones estratégicas, ni los Estados Unidos ni ninguno de los países europeos admitieron la existencia de casos de gripe hasta que el Inspector General de Sanidad de España comunicó su presencia a la Oficina Internacional de Higiene, y la prensa general informaba de ello fuera de nuestras fronteras, ante la ausencia de censura militar, dada la no participación de nuestro país en el conflicto bélico.

Está bien documentada la presencia de gripe en el campamento militar de Fort Riley (Kansas) de los Estados Unidos el 4 de marzo de 1918, ${ }^{3}$ aunque investigaciones recientes han planteado la existencia de brotes algunos meses antes en la mayoría de los campamentos

3 CROSBY, Alfred W. Epidemic and Peace, 1918. Westport: Greenwood, 1976. 
militares estadounidenses. ${ }^{4}$ Desde Estados Unidos se difundió a Europa, mediante el traslado en barco de soldados hasta Brest (Francia), en donde apareció la enfermedad a principios de abril. Desde Francia se introdujo a España mediante el retorno de trabajadores temporeros españoles y, a través de los soldados portugueses, que volvían del frente en ferrocarril atravesando buena parte del norte de España. El inicio se produjo en Madrid a primeros de mayo, aunque el estallido se constató coincidiendo con las fiestas de San Isidro a mediados de dicho mes, favorecido por las aglomeraciones de la población con motivo de las verbenas y la romería en honor del santo, patrón de dicha localidad. ${ }^{5}$ En este contexto festivo, pero a la vez de crisis política, económica y social en España, comenzó el primer brote epidémico de esta crisis sanitaria, que fue seguido de dos episodios más, en otoño de 1918 y en la primavera de $1919 .{ }^{6}$ Aunque en Madrid alcanzó mayor gravedad el brote de la primavera de 1918, en la mayoría del país fue el segundo más grave, como señalaron Beatriz Echeverri (1993), ${ }^{7}$ Josep Bernabeu Mestre (1991), ${ }^{8}$ Manuel Martínez en Valencia, ${ }^{9}$ y ha sido puesto de relieve en varias tesis doctorales que han estudiado el desarrollo de esta pandemia en Bilbao, Salamanca, Zamora y Cuenca. ${ }^{10}$

Volviendo la mirada hacia los años previos a la pandemia buscando indicios que advirtieran de cambios que podían desembocar en la gran crisis sanitaria causada por la gripe, algunos autores han señalado el aumento de morbilidad y mortalidad por gripe y otras enfermedades respiratorias, entre ellas bronconeumonías, a partir de diciembre de 1915, pero sobre todo en 1916 y 1917, que ocurrieron en los frentes de batalla del conflicto bélico, pero también en ciudades de Estados Unidos, Gran Bretaña, Francia o Japón. Este fenómeno se produjo igualmente en España. ${ }^{11}$

A diferencia de lo que suele ser habitual en el caso de la gripe, la población más afectada fue la adulta joven (20-39 años), en vez de los mayores de 60 años y menores de 1 año, alcanzando un total de 270.000 muertes. ${ }^{12}$ Esta preferencia etaria significó una afectación predominante de la población activa, cuyo quebranto impactó más fuertemente en la actividad diaria del país y de cada ciudad y pueblo, que quedaron paralizados totalmente o en una gran medida. La magnitud de esta crisis sanitaria se tradujo no sólo en un aumento de la mortalidad por gripe, sino también por otras enfermedades respiratorias (neumonía, bronquitis crónica y tuberculosis pulmonar) y su impacto en la elevación de las cifras de la tasa bruta de mortalidad,

4 MATA, Santiago. Cómo el Ejército Americano Contagió Al Mundo la Gripe Española. Madrid: Ediciones Amanecer, 2017.

5 EI Sol, Madrid, p. 3, 22 mayo 1918. PORRAS-GALLO, María-Isabel. Un reto para la sociedad madrileña: la epidemia de gripe de 1918-1919. Madrid: Editorial Complutense-Comunidad de Madrid, 1997. p. 41

6 PORRAS-GALLO, op. cit., 1997, p. 41-68.

7 ECHEVERRI DÁVILA, Beatriz. La Gripe Española: La pandemia de 1918-1919. Madrid: CIS-Siglo XXI, 1993.

8 BERNABEU MESTRE, Josep (coord.). La ciutat davant el contagi. Alacant i la grip de 1918-1919. Alacant: Generalitat Valenciana, Conselleria de Sanitat, 1991.

9 MARTÍNEZ, Manuel. Vàlencia al límit. La ciutat davant l'epidemia de gripe de 1918. Simat de la Valldigna (Valencia): Edicions La Xara, 1999.

10 Una relación de estas tesis doctorales figuran en PORRAS-GALLO, op. cit., 1997, p. 145-147.

11 PORRAS-GALLO, María-Isabel. Una ciudad en crisis: la epidemia de gripe de 1918-19 en Madrid. Tesis (Doctorado en Ciencias Sociosanitarias) Facultad de Medicina. Universidad Complutense. Madrid, 1994a. p. 70-73.

12 ECHEVERRI DÁVILA, op. cit., p. 120-122. 
que comparada con los años anteriores y posteriores, permite corregir el subregistro por gripe, dada la dificultad en ocasiones para hacer un diagnóstico clínico de la enfermedad..$^{13}$

Conviene recordar que, como adelanté, la gripe de 1918-1919 se desarrolló en un contexto muy crítico para España, pese a no participar en el conflicto bélico y haberse beneficiado a nivel macroeconómico de las actividades comerciales realizadas con el exterior, que tuvieron como contrapartida negativa la falta de suministros de los productos de primera necesidad dentro del país y su encarecimiento, que fue sufrido en mayor medida por la población más vulnerable. Ésta se encontró con grandes dificultades para acceder a los alimentos y a los medicamentos más utilizados para tratar la gripe, pero también más expuesta al contagio y a una peor evolución de la enfermedad, como consecuencia del hacinamiento en viviendas pequeñas e insalubres. Tampoco eran mejores las condiciones laborales, con jornadas interminables, bajo salario o la frecuente falta de empleo. De modo que, por ejemplo, en la ciudad de Madrid fueron los distritos municipales menos favorecidos y los que contaban con mayor número de instituciones sanitarias y sociales, los que registraron una mayor mortalidad. ${ }^{14}$

Además, existían importantes deficiencias científico-sanitarias, que se habían señalado periódicamente desde finales del siglo $\mathrm{XIX}^{15}$ y que no habían sido corregidas con la aprobación de la Instrucción General de Sanidad de 1904 y su aplicación, ni en los años posteriores previos a la pandemia, como se puso de relieve en numerosas ocasiones a través de la prensa general, pero también de las revistas profesionales de Medicina, Farmacia y Veterinaria, y, muy gráficamente, en el Discurso de Ingreso en la Real Academia Nacional de Medicina de Manuel Martín Salazar (1913) ${ }^{16}$ y cuando fue presentado un Proyecto de Ley de Epidemias al Parlamento en $1915 .{ }^{17}$ Se consideraba que faltaba una legislación sanitaria adaptada a las características de la Medicina de esos momentos, ${ }^{18}$ instituciones científico-sanitarias capaces de permitir la investigación científica al nivel de los países de nuestro entorno y de proporcionar atención hospitalaria a personas con enfermedades infecciosas, profesionales bien preparados e independientes de los poderes públicos que pudieran desempeñar las labores de Salud Pública desde el nivel municipal al estatal, pasando por el provincial con una dedicación a tiempo completo. ${ }^{19}$ Junto a todo lo anterior, se juzgaba igualmente clave

13 BERNABEU MESTRE, Josep. Enfermedad y población. Introducción a los problemas y métodos de la epidemiología histórica. Valencia: Seminari d’Estudis sobre la Ciencia, 1995.

14 PORRAS-GALLO, op. cit., 1997, p. 52-60.

15 HAUSER, Philip. Madrid bajo el punto de vista médico-social. Madrid, 2 vols., v. 2, p. 8-11, 1902 (Se cita por la edición preparada por MORAL, Carmen del, Madrid: Editora Nacional, 1979).

16 MARTÍN SALAZAR, Manuel. La Sanidad en España. Madrid: Imprenta del Colegio Nacional de Sordomudos y de Ciegos, 1913. p. 157-161.

17 PORRAS-GALLO, María-Isabel. La profilaxis de las enfermedades infecciosas tras la pandemia gripal de 191819: Ios seguros sociales. Dynamis, v. 13, p. 279-293, 1993; PORRAS-GALLO, María-Isabel. La lucha contra las enfermedades 'evitables' en España y la pandemia de gripe de 1918-19. Dynamis, v. 14, p. 159-183, 1994b.

18 De hecho, Manuel Martín Salazar había solicitado la aprobación de una nueva Ley de Protección de la Salud Pública. MARTíN SALAZAR, op. cit.

19 Una detallada descripción de la situación higiénico-sanitaria de España y de las reformas que precisaba el país para mejorar la Salud Pública fue expuesta por Manuel Martín Salazar en su discurso de Ingreso en la Real Academia Nacional de Medicina, recogiendo en buena medida algunas de las denuncias y soluciones planteadas unos años antes por Philip Hauser (1902). MARTíN SALAZAR, op. cit. 
para mejorar la situación que España contara con un Ministerio de Sanidad. ${ }^{20}$ A pesar de las deficiencias señaladas, la Medicina del momento se consideraba capaz de ocuparse de los procesos infecciosos con cierta solvencia, dados los conocimientos y recursos que, en su opinión, estaba aportando la Bacteriología. Una vez identificado y aislado el germen causante de la enfermedad, se trataba de preparar la vacuna y el suero específicos para disponer de medios profiláctico y terapéutico eficaz. ${ }^{21}$

\section{La actividad diaria de los médicos durante la pandemia: crisis y oportunidad}

EL DESENCADENAMIENTO DE LA PANDEMIA de gripe de 1918-1919 trastocó la actividad diaria de los médicos. La crisis sanitaria exigió de ellos no sólo un incremento de su labor asistencial habitual, sino que desentrañaran la naturaleza del problema sanitario que se presentaba de modo epidémico. Debían atender tanto a efectuar el diagnóstico de cada uno de sus pacientes, cuyo número se incrementaba por momentos desde el inicio de mayo de 1918, como a proporcionar una respuesta colectiva sobre el problema sanitario a una sociedad que se inquietaba por momentos. En uno y otro caso estaban obligados por su condición de expertos y por los deberes que imponía su profesión hacia la ciudadanía, colocando la salud de sus pacientes por encima de la suya, lo que se tradujo en que, en ocasiones, resultaran contagiados, desarrollaran la enfermedad e incluso fallecieran. Recordemos además la falta de un sistema sanitario medianamente articulado y la ausencia de instauración del seguro obligatorio de enfermedad y otros seguros sociales. ${ }^{22}$

La observación del cuadro clínico les debía permitir desvelar cuál era la naturaleza del problema epidémico presente. Si al inicio del primer brote se convino que se trataba de la gripe, cuando comenzó el segundo se presentaron las dudas y se barajaron diversos diagnósticos diferenciales, que iban desde la peste, el dengue, la fiebre amarilla o la gripe que volvía con el comienzo del otoño y adquiría una mayor gravedad que en la primavera de 1918. El establecimiento de la patología presente iba ligado a la elaboración por los médicos de un discurso explicativo sobre su clínica, etiología, tratamiento, profilaxis y modo de efectuar un diagnóstico certero y diferencial con respecto a otras patologías respiratorias. Este último punto

20 Hauser lo indicó en 1884. HAUSER, op. cit. Las solicitudes de un Ministerio de Sanidad durante el primer tercio del siglo XX ha sido estudiado en varios trabajos, entre ellos los de VALENZUELA, José; RODRÍGUEZOCAÑA, Esteban. La política sanitaria ante la crisis epidémica de 1918. Reivindicación de un Ministerio de Sanidad. In: VALERA, Manuel; EGEA, María Ángeles; BLÁZQUEZ, María Dolores (eds.). Libro de Actas. VIII Congreso Nacional de Historia de la Medicina, Murcia-Cartagena, diciembre 1986. Murcia: Universidad de Murcia, 1988, v. 1, p. 514-523; HUERTAS GARCÍA-ALEJO, Rafael. El debate sobre la creación del Ministerio de Sanidad en la España del primer tercio del siglo XX. Discurso ideológico e iniciativas políticas, Asclepio, v. 45, n. 1, p. 89-122, 1993.

21 Era por eso por lo que las enfermedades infecciosas se consideraban evitables. PORRAS GALLO, op. cit., 1994b.

22 PORRAS-GALLO, María-Isabel. Un foro de debate sobre el seguro de enfermedad: las conferencias del Ateneo de Madrid de 1934. Asclepio, v. 51, n. 1, p. 159-184,1999; PORRAS-GALLO, María-Isabel. Between the German Model and Liberal Medicine: The Negotiating Process of the State Health Care System in France and Spain (1919-1944). Hygiea Internationalis, v. 6, p. 135-149, 2007. 
fue clave y reveló las distintas posturas correspondientes a los diferentes profesionales de la Medicina y el tránsito que se estaba dando en el diagnóstico de las enfermedades infecciosas y en el papel privilegiado que, desde algunas instancias, se quería asignar al laboratorio. Para buena parte de los clínicos los síntomas apoyaban el diagnóstico de gripe y el tratamiento que debían aplicar, seguía casi sin cambios la línea terapéutica sintomática aplicada también en la anterior pandemia de 1889-1890, a la que se debía añadir el uso de sueros, aunque la consideración de este nuevo elemento provocó también discrepancias. Si para algunos, cualquier suero - como el antidiftérico - era una buena herramienta porque estimulaba las defensas generales del organismo, ${ }^{23}$ para un número mayor de facultativos el suero debía ser específico contra el agente de la gripe ${ }^{24}$ requiriéndose entonces la intervención del laboratorio para fijar la etiología de la enfermedad.

El uso del laboratorio era requerido también por algunos clínicos, porque consideraban ineludible confirmar por esa vía el diagnóstico que la clínica proponía, y por los higienistas, que juzgaban clave su papel para enfocar el tratamiento y, sobre todo, la profilaxis pública de la pandemia de gripe de 1918-1919 de modo más específico, que con las tradicionales medidas de la Higiene pública (aislamiento, cuarentenas, cordones sanitarios, limpieza de vías públicas, mataderos...) usadas frente a las epidemias. ${ }^{25}$ El laboratorio debía, por tanto, fijar cuál era el germen de la gripe mediante el aislamiento del bacilo de Pfeiffer, postulado por Richard Pfeiffer en $1892^{26}$ o el de otro que estuviera presente y cumpliera los postulados de Koch. Sin embargo, al igual que fuera de nuestras fronteras, ${ }^{27}$ no fue posible ni una ni otra cosa, aislándose diversos gérmenes, solos o conjuntamente, lo que llevó a plantear diferentes etiologías bacterianas (bacilo de Pfeiffer, estreptococos, neumococos...), a confesar abiertamente que se desconocía cuál podía ser el germen de la gripe o a proponer que el agente sería un virus filtrable, siendo minoritarias estas dos últimas opciones. ${ }^{28}$

El problema de la etiología de la gripe, por tanto, quedó sin clarificar al final de la pandemia. No fue sólo una falta de medios (microscopio electrónico o procedimientos apropiados para cultivar el virus de la gripe y efectuar la experimentación animal), sino que lo más relevante fue la falta de consenso entre los profesionales, como se había logrado con anterioridad con otras enfermedades víricas, como la viruela. Sin embargo, el reto que supuso la crisis sanitaria en el particular contexto señalado, favoreció que un número mayor de médicos de la Sanidad civil y militar, así como otros profesionales sanitarios, llevaran a cabo labores de investigación

23 PORRAS-GALLO, María-Isabel. Sueros y vacunas en la lucha contra la pandemia de gripe de 1918-1919 en España. Asclepio, v. 60, n. 2, p. 261-288, 2008.

24 Ibidem, p. 271-276.

25 Ibidem, p. 276-278.

26 THÉODORIDES, Jean. La microbiología médica. In: LAÍN ENTRALGO, Pedro (dir.). Historia Universal de la Medicina, v. 6. Barcelona: Salvat, p. 175-192, 1974. p. 188.

27 TOGNOTTI, Eugenia. Scientific Triumphalism and Learning from Facts: Bacteriology and the 'Spanish Flu' Challenge of 1918. Social History of Medicine, v. 16, n. 1, p. 97-110, 2003.

28 PORRAS-GALLO, op. cit., 2008; PORRAS-GALLO, op. cit., 1997, p. 103-107. 
sobre el agente de la gripe, pero también sobre la puesta a punto de nuevos sueros y vacunas contra los gérmenes que iban aislando en sus laboratorios. Esta actividad investigadora dio lugar, por un lado, a los sueros antiestreptocócico y antineumocócico, que fueron empleados separadamente, al igual que el antidiftérico, y, por otro, a varias vacunas que iban dirigidas sólo contra el bacilo de Pfeiffer o el neumococo o contra varias de las bacterias aisladas. Pese a que su aplicación fue bastante limitada, por no haber estado disponibles hasta mediados o finales del segundo brote pandémico, los sueros y las vacunas alcanzaron mayor valor social y se percibió la rentabilidad de la creación de laboratorios privados por los propios médicos, materializándose algunas iniciativas en 1918 y 1919. ${ }^{29}$ Podemos decir, por tanto, que la pandemia de gripe contribuyó a consagrar esta nueva actividad laboral y darle mayor visibilidad dentro de la profesión médica de nuestro país, que participó desde el laboratorio o colaboró desde la sala o el servicio de hospital que dirigía o en donde desarrollaba su trabajo clínico para facilitar el ensayo de los sueros y vacunas preparados. Como veremos más adelante, las nuevas expectativas científico-profesionales que se habían abierto atrajeron también la atención de farmacéuticos y veterinarios. ${ }^{30}$

La gripe de 1918-1919, por tanto, no fue sólo una situación crítica a la que los médicos debieron dar respuesta, sino también una oportunidad científica para una parte de este colectivo. Ahora bien, los esfuerzos efectuados desde la Medicina no consiguieron minimizar la pandemia, alcanzando gran gravedad, como hemos señalado. Este hecho motivó que, fundamentalmente durante el segundo brote epidémico, una parte del sector médico relacionara dicha gravedad con las desigualdades socioeconómicas (malas condiciones de vivienda y de trabajo, el hacinamiento, la escasez y carestía de alimentos, medicamentos y productos de primera necesidad) de la población trabajadora y las carencias sanitarias presentes en España en aquel momento, que ya hemos mencionado. ${ }^{31}$ De ahí que demandaran al gobierno medidas que corrigieran esas deficiencias e incluso que hicieran sus propias propuestas insertadas dentro de las peticiones profesionales del colectivo médico.

$Y$ es que la crisis sanitaria constituyó igualmente una excelente ocasión para que los médicos presentaran nuevamente sus demandas profesionales ante las autoridades y la sociedad en su conjunto. De hecho, paralelamente a las actividades señaladas anteriormente, los profesionales de la Medicina continuaron con la campaña de defensa de la clase médica, que habían iniciado un año antes de empezar la pandemia de gripe, y que esa crisis sanitaria le dotaba de un mayor protagonismo. Así, en mayo de 1918, la campaña había alcanzado ya las dos Cámaras Parlamentarias, tras haber estado precedida por la acción liderada por

29 Algunos de los que se formaron fueron el Instituto THIRF (fundado por Tello, Hidalgo, Illera, Ramón y Falcó a finales de 1918) y el Laboratorio IBYS (fundado por Gustavo Pittaluga en 1919). Ambas instituciones fueron fusionadas en 1929, bajo el nombre IBYS. PORRAS-GALLO, op. cit., 1994a.

30 PORRAS-GALLO, María-Isabel.Renovación y reorganización profesional en tiempo de crisis: farmacéuticos y veterinarios durante la gripe de 1918-1919 en España. Varia Historia, Belo Horizonte, v. 25, n. 42, p. 477-498, jul.-dez. 2009; PORRAS-GALLO, op. cit., 1997, p. 109-114.

31 PORRAS-GALLO, op. cit., 1997, p. 108. 
el Colegio Oficial de Médicos de la provincia de Madrid y la colaboración de las principales Sociedades Científicas y las Academias de Medicina. ${ }^{32}$ El objetivo principal de la campaña era lograr mejorar la instalación social de los médicos en ese nuevo entorno establecido tras la Primera Guerra Mundial. ${ }^{33}$ De ahí que algunas de sus primeras demandas pasaban por mejorar su formación científico-práctica para que su título adquiriera mayor valor, lo que, en su opinión, exigía disponer de una nueva Facultad de Medicina en la capital del país, que permitiera una enseñanza médica moderna y adaptada al nivel de la nueva ciencia médica destinada a un número menor de estudiantes, reclamándose también la limitación del número anual de titulados. Unido a lo anterior solicitaban la colegiación obligatoria de todos los médicos para poder ejercer, algo que lograrían y que daría lugar a la aparición de nuevos Colegios en aquellas provincias españolas en las que todavía no existían, como fue el caso, por ejemplo, de Ciudad Real. ${ }^{34}$ Ahora bien, su plan era más ambicioso y se articuló a nivel parlamentario mediante la constitución de la Junta de diputados médicos en el Congreso o Cámara Baja y el nombramiento de una Comisión en el Senado o Cámara Alta. Mientras que la primera estaba integrada por los diputados médicos, bajo la presidencia de José Francos Rodríguez, que además de médico fue alcalde de Madrid; la segunda estaba integrada por los senadores Ángel Pulido, Carlos María Cortezo y Amalio Gimeno, académicos de Medicina y figuras clave, que ya habían ocupado cargos políticos - como la Inspección General de Sanidad - o los ocuparían en el bienio de la pandemia de gripe, como el último que fue uno de los Ministros de Gobernación, ${ }^{35}$ que tenía responsabilidad sobre la Sanidad a falta de un Ministerio propio para estas competencias. ${ }^{36}$

Con la llegada del segundo brote de la pandemia y la constatación de su mayor gravedad, en este sector activo de la clase médica se reavivó la idea de la urgencia de aprobar una nueva ley de Sanidad para sustituir a la Instrucción General de Sanidad de 1904. Se pretendía con ello corregir algunas de las insuficiencias derivados de dicha norma legal y modernizar científica y sanitariamente España. Fue por eso por lo que, junto a demandas concretas y más limitadas, como la mejora de las condiciones de los médicos rurales o la construcción de un hospital para enfermedades infecciosas en Madrid, entre otras, se diseñaron cuatro proyectos de ley centrados en la profilaxis pública de dichos procesos patológicos, que fueron presentados y discutidos en el Congreso de los Diputados entre 1919 y 1922, pero no fueron aprobados. ${ }^{37}$

32 Política sanitaria, Boletín del Colegio de Médicos de la provincia de Madrid, mayo de 1918, p. 9; PORRASGALLO, op. cit., 1997, p. 103-104.

33 JUARROS, César. La opinión de los políticos. Dice Sánchez Guerra. Boletín del Colegio de Médicos de la provincia de Madrid, p. 1-2, 16 abril 1917.

34 COLEGIO OFICIAL DE MÉDICOS DE CIUDAD REAL. 1918-2018. Cien años del Colegio Oficial de Médicos de Ciudad Real. Ciudad Real: Diputación Provincial de Ciudad Real, 2019.

35 MATILLA GÓMEZ, Valentín. 202 Biografías Académicas. Madrid: Real Academia Nacional de Medicina, 1987.

36 A falta de un Ministerio de Sanidad, todo lo relacionado con la salud y sanidad era gestionado desde la Inspección General de Sanidad, que era una de las Inspecciones Generales del Ministerio de Gobernación. Esta situación tenía muchos efectos negativos, entre ellos la menor atención y financiación que recibía. PORRAS-GALLO, op. cit., 1994a.

37 Con anterioridad, en 1914, se había realizado otro intento similar preparando y presentando un Proyecto de ley de Epidemias. PORRAS-GALLO, op. cit., 1994b. 
Una iniciativa similar había sido presentada en Alemania en marzo de $1918 .{ }^{38}$ Pese a que no prosperaran estas iniciativas, resultan muy relevantes porque muestran, por un lado, cómo la pandemia estimuló el debate de renovación científico-sanitaria del país y, por otro, cómo algunos de dichos proyectos incorporaron medidas para atender a esas desigualdades socioeconómicos, que sufría especialmente la clase trabajadora, y que algunos profesionales de la Medicina habían relacionado con el mayor impacto de la gripe de 1918-1919. Estos proyectos de ley fallidos fueron la respuesta al insuficiente Real Decreto de 10 de enero de 1919 de prevención de enfermedades contagiosas, iniciativa de Amalio Gimeno, siendo Ministro de Gobernación.

La primera de estas cuatro iniciativas legislativas fallidas, bajo el nombre proyecto de Ley sobre profilaxis pública de las enfermedades infecciosas, fue preparada por Julián van Baumberghen, un Inspector de trabajo que tuvo una intensa actividad parlamentaria centrada fundamentalmente en el mundo del trabajo y en cuestiones sanitarias. ${ }^{39}$ Se presentó en el Congreso de Diputados en julio de 1919 y poseía como particularidad, respecto al proyecto de ley de epidemias de 1914, la incorporación de algunos elementos relacionados con la consideración de la Medicina como ciencia social, ${ }^{40}$ entre los que figuraron la necesidad de efectuar la socialización del trabajo y su reglamentación, así como la socialización de las asistencias social y sanitaria. Sin embargo, en dicho proyecto de ley aún no se incluyó el establecimiento de los seguros sociales como un recurso apropiado para contribuir a la profilaxis pública de las enfermedades infecciosas, que sí formó parte de la segunda de estas iniciativas legales, presentada el 13 de noviembre de 1919 por el ministro de la Gobernación, Manuel de Burgos Mazo. Manuel Martín Salazar, médico militar e higienista, que fue Inspector General de Sanidad, y Amalio Gimeno fueron los autores de este nuevo proyecto, que tampoco prosperó. Tras casi dos años, Manuel Martín Salazar reelaboró el proyecto en colaboración con Ángel Pulido, logrando que lo presentaran sucesivamente, Bugallal, Burgos, Coello y Piniés, que fueron los ministros de la Gobernación entre 1921 y mayo de 1922. Pese a bastantes similitudes de contenido de estos nuevos textos legales, hubo también diferencias. De hecho, en la versión de mayo de 1922, ya no figuraron los seguros sociales, aunque se siguió manteniendo elementos de la Medicina social, como los seguros de enfermedad y de maternidad, acompañados de medidas para luchar contra

38 El 25 de marzo de 1918 fue presentado en Alemania un proyecto de ley de profilaxis «contra las enfermedades que minan y destruyen las razas», siendo celebrada esta iniciativa en las páginas del diario $A B C$, desde donde se reconocía que una ley similar sería muy bienvenida en España. ABC en Alemania. Una ley de profilaxis, ABC, p. 3, 25 marzo 1918.

39 Proposición de ley del Sr. Van-Baumberghen, sobre profilaxis pública de las enfermedades infecciosas, Diario de Sesiones de Cortes. Congreso de los Diputados, Apéndice 5, 21, p. 1-13, 30 julio. Proyecto de ley presentado por el señor ministro de la Gobernación, sobre profilaxis pública de las enfermedades infecciosas, [Siglo Médico, n. 9442, p. 1041-1045, 29 noviembre de 1919; Siglo Médico, n. 3443, p. 1068-1070, 6 diciembre 1919; Siglo Médico, n. 9444, p. 1083-1089, 13 diciembre 1919.

40 Las medidas incluidas en los proyectos hablan a favor de la influencia que estaban ejerciendo, en esos momentos, los elementos teóricos de la Medicina Social: la cuantificación de los fenómenos demográficos, el valor económico de la salud, la etiología social y la consideración de la Medicina como Ciencia Social, RODRÍGUEZ OCAÑA, Esteban. La constitución de la Medicina Social como disciplina en España (18821923). Madrid: Ministerio de Sanidad y Consumo, 1987. p. 17-28. 
la mortalidad infantil y otras de la higiene escolar, pero también de medidas características de la higiene industrial con las que se pretendía igualmente mejorar el ambiente y las condiciones del trabajo. ${ }^{41}$

Como ya he adelantado, estos cuatro proyectos legislativos otorgaron también un lugar importante a la adopción de medidas que favorecieran la modernización científico-sanitaria del país apoyándose en el desarrollo de una medicina bacteriológica, que fomentaba la aparición y/o extensión de instituciones a tal fin y algunas mejoras referentes a la formación y práctica médica en el campo de las enfermedades infecciosas. ${ }^{42}$ Se buscaba reforzar el papel del laboratorio y la producción y utilización de sueros y vacunas en la lucha contra dichos procesos patológicos. Esto motivó que una parte de los farmacéuticos y, en menor medida, de los veterinarios reivindicara su participación en esa medicina bacteriológica e incluso su preferencia frente a los médicos, en un contexto marcado también por una etapa de reorganización profesional de estos colectivos. ${ }^{43}$ Precisamente, este contexto reivindicativo de las tres profesiones sanitarias y los desacuerdos entre ellas, así como dentro de la propia clase médica, fueron una rémora para los sucesivos intentos de aprobar una nueva ley, casi más que la falta de recursos reales del país para afrontar la puesta en marcha de las medidas incluidas en estos ambiciosos proyectos legislativos. Resultado de todo ello fue que, en vez de lograrse una reforma global, se aprobó el Real Decreto de 10 de enero de 1919 de prevención de enfermedades contagiosas, ${ }^{44}$ bastante limitado, y pequeñas medidas contenidas en Reales Órdenes, como el establecimiento de laboratorios municipales, la dotación de terrenos para construir un hospital de Epidemias en Madrid, algunos cambios organizativos de la Sanidad y la Beneficencia, el Reglamento para la elaboración y venta de especialidades farmacéuticas y el relativo a la elaboración y venta de vacunas y sueros o la petición al Instituto Nacional de Previsión de la redacción de un anteproyecto de ley sobre el seguro de paro forzoso. ${ }^{45}$

41 Proyecto de ley de profilaxis de enfermedades evitables [Medicina Ibera, p. CLXXVI, 24 junio 1922; Medicina Ibera, p. XVI, 1 julio 1922; Medicina Ibera, p. XXXVI, 8 julio 1922; Medicina Ibera, p. LV,I 15 julio 1922,]; Dictamen de la Comisión de Gobernación sobre profilaxis pública de las enfermedades evitables [Medicina Ibera, p. XC, 29 julio 1922; Medicina Ibera, p. CVIII, 5 agosto 1922; Medicina Ibera, p. CXXVI, 12 agosto 1922; Medicina Ibera, p. CXLN, 19 agosto 1922].

42 El contenido y los argumentos justificativos de estos cuatros proyectos de ley para la profilaxis pública de enfermedades infecciosas han sido estudiados por PORRAS-GALLO, op. cit., 1994b.

43 PORRAS-GALLO, op. cit., 2009.

44 Real Decreto del Ministerio de Gobernación del 10 de enero de 1919 relativo a la prevención de enfermedades infecciosas. Gaceta de Madrid, v. 46, p. 579-581, 15 febrero 1919.

45 Real Orden del Ministerio de Gobernación del 3 de octubre de 1918 relativa al establecimiento de laboratorios municipales. Gaceta de Madrid, v. 278, p. 57, 5 octubre 1918; Real Decreto del Ministerio de Hacienda del 3 de diciembre de 1918 relativo a la aprobación del concurso celebrado para la adquisición de unos terrenos. Gaceta de Madrid, v. 337, p. 854, 3 diciembre 1918; Real Decreto del Ministerio de Gobernación del 31 de enero de 1919 relativo a la nueva organización sanitaria del Ministerio de Gobernación. Gaceta de Madrid, v. 46, p. 579581, 15 febrero 1919; Real Decreto del Ministerio de Gobernación del 6 de marzo de 1919 relativo al Reglamento de para la elaboración y venta de especialidades farmacéuticas. Gaceta de Madrid, v. 72, p. 934-936, 13 marzo 1919; Real Decreto del Ministerio de Gobernación del 10 de octubre de 1919 relativo al Reglamento de para la elaboración y venta de vacunas y sueros. Gaceta de Madrid, 13 octubre 1919; Real Orden del Ministerio de Gobernación encargando al Instituto Nacional de Previsión la redacción de un anteproyecto de Ley sobre el seguro de paro forzoso. Gaceta de Madrid, v. 269, p. 1026-1027, 26 septiembre 1919. 


\section{El trabajo de los farmacéuticos durante la gripe de 1918-1919: demandas y apertura hacia nuevos ámbitos de actuación}

El desarrollo de la Primera Guerra Mundial condicionó en buena medida la actividad laboral de la farmacia ante las dificultades para poder contar con medicamentos y principios activos para su preparación, dada la alteración comercial que impuso la contienda y el aumento de la demanda de algunas de estas sustancias para uso entre la población militar, que participaba en el conflicto. Consecuencia de todo ello no fue solo la escasez, sino también la carestía de los medicamentos que impactó negativamente entre los profesionales de la farmacia en España. De modo que una parte mayoritaria de este colectivo responsabilizaba a estas circunstancias de su "aflictiva y precaria situación" que la Unión Farmacéutica Nacional, Federación voluntaria que agrupaba a todos los Colegios Provinciales de Farmacéuticos de España, reconocía en la reunión de su Junta Directiva de abril de $1918 .{ }^{46}$ Sin embargo, una parte de la clase farmacéutica entendía que la situación por la que pasaba no era algo coyuntural, mostrando su convencimiento de que la razón de ello era algo más profundo relacionado con la transformación que se estaba produciendo a nivel científico y tecnológico desde finales del siglo XIX, que afectaba a la práctica sanitaria y estaba alcanzando también la actividad farmacéutica, que no podía ser ajena al creciente papel que la industria farmacéutica estaba desempeñando. Se estaba, por tanto, transformando la actividad diaria del farmacéutico tradicionalmente ligada a la preparación de fórmulas magistrales y venta de medicamentos, cuya elaboración controlaba, pero que ya se había extendido desigualmente a la comercialización de medicamentos fabricados industrialmente en las últimas décadas.

Sin duda, el impacto negativo de esta transformación se hizo más visible con el desarrollo del conflicto bélico mundial y, aún más, con el desarrollo de la pandemia de gripe de 19181919, que implicaba una mayor demanda de los medicamentos necesarios para tratar dicha patología en un contexto complejo, marcado por las complicaciones comerciales indicadas. Lo que suponía, en ocasiones, no contar con los recursos para atender debidamente las necesidades de sus comunidades, siendo particularmente doloroso en las pequeñas comunidades rurales, donde estos profesionales se implicaban más en dichas sociedades. $Y$, en otras, ofrecer unos medicamentos a unos precios elevados, que dificultaba su acceso a la población menos favorecida y se traducía con frecuencia en una negativa valoración social de los farmacéuticos.

Ahora bien, al igual que ocurrió con la clase médica, parte del sector farmacéutico percibió que la pandemia era también una oportunidad para mejorar la situación de este colectivo profesional, particularmente, una vez que ya se habían dado algunos pasos para su fortalecimiento, como el establecimiento de la colegiación obligatoria para el ejercicio, ${ }^{47}$

46 JUNTA DIRECTIVA EN PLENO DE LA UNIÓN FARMACÉUTICA NACIONAL. Unión Farmacéutica Nacional. La Farmacia Moderna, v. 12, p. 98-99, 25 junio 1918.

47 La aprobación de esta medida implicaba en la práctica que ningún farmacéutico o farmacéutica podía ejercer 
siguiendo la senda de los médicos y aprovechando el espíritu renovador presente en buena parte de la sociedad en esos primeros años del siglo XX. De hecho, este sentir lo había verbalizado el presidente del Colegio de Farmacéuticos de Madrid al inicio de 1918. ${ }^{48}$ Aunque se consideraron básicamente dos modos distintos de actuar, sí hubo coincidencia en que el momento de la acción había llegado. ${ }^{49}$ Como se convino desde la Unión Farmacéutica Nacional, la gripe de 1918-1919 había colocado las cuestiones sanitarias en el punto de mira de los distintos sectores de la sociedad, incluyendo a algunos partidos políticos. Ofreciéndose, por tanto, una gran oportunidad para plantear sus reivindicaciones profesionales y mejorar su posicionamiento social, compitiendo en algunos casos con la clase médica. ${ }^{50}$

Conforme a los objetivos de este trabajo, no me voy a ocupar de la totalidad de las medidas adoptadas durante la pandemia para tratar de reorganizar la profesión farmacéutica, ${ }^{51}$ sino únicamente de aquellas que destacaban la capacitación de estos profesionales para el desempeño de nuevas tareas conectadas con el abordaje bacteriológico de las enfermedades infecciosas, y defendían ser más idóneos para asumirlas que los profesionales de la Medicina. Desde esta perspectiva, paralela y complementaria del mantenimiento de la "reivindicación de sus derechos" frente a la sociedad, se buscaba ampliar la actividad farmacéutica en esos nuevos campos que se estaban abriendo. ${ }^{52}$ Ello exigía mostrar que la clase farmacéutica poseía una cultura científica al mismo nivel o incluso por encima de la de los médicos. Se trataba, por tanto, de estar presente en aquellos círculos en los que en esos años se debatía y se tomaban decisiones sobre los principales aspectos que afectaban a las cuestiones internas de las diferentes ciencias y sobre las respuestas a dar ante los problemas sociales. Uno de estos círculos principales eran las Academias, aunque J. P. Franco consideraba que era preciso mostrar también el conocimiento científico de los farmacéuticos en otros foros, como la prensa diaria, que permitía efectuar una labor divulgadora de ese saber especializado a la sociedad, ${ }^{53}$ en un momento en que este medio alcanzaba mayor protagonismo social.

Llevar a la práctica lo planteado por J. P. Franco significaba la asunción de tareas investigadoras y de divulgación científica por parte de los profesionales de la Farmacia, que durante la pandemia de 1918-1919 se tradujeron en competir con los médicos por aclarar la etiología de la gripe y trabajar por la puesta en marcha de recursos profilácticos y/o terapéuticos. Esta línea de actuación fue seguida por una minoría y encontró las mismas dificultades que

su profesión en cualquier punto del país sin haberse afiliado al Colegio de Farmacéuticos de la provincia en la que iba a desarrollar su actividad.

48 Colegio Provincial de Farmacéuticos de Madrid. El Monitor de la Farmacia y de la Terapéutica, v. 23, p. 6263, p. 62, 5 febrero 1918.

49 JUNTA DIRECTIVA EN PLENO DE LA UNIÓN FARMACÉUTICA NACIONAL. Unión Farmacéutica Nacional. La Farmacia Moderna, v. 12, p. 98-99, 25 junio 1918; JUNTA DIRECTIVA EN PLENO DE LA UNIÓN FARMACÉUTICA NACIONAL. Unión Farmacéutica Nacional. A los farmacéuticos españoles en ejercicio. La Farmacia Moderna, v. 13, p. 106-107, 10 julio 1918.

50 UNIÓN FARMACÉUTICA NACIONAL. Circular a los Colegios. EI Monitor de la Farmacia y la Terapéutica, v. 833 , p. 510-512, p. 511, 15 noviembre 1918.

51 Este tema ha sido analizado en profundidad en: PORRAS-GALLO, op. cit., 2009; PORRAS-GALLO, op. cit., 1997; PORRAS-GALLO, op. cit., 1994a.

52 FRANCO, J. P. Rumbo que se impone. La Farmacia Española, p. 769-773, 5 diciembre 1918. p. 771.

53 Ibidem. 
la clase médica, se topó con los resultados poco clarificadores que ofrecía el laboratorio, que llevó a algunos farmacéuticos a hacer propuestas etiológicas similares a los médicos. ${ }^{54}$ En ocasiones, como ocurrió con César Chicote, su labor fue tanto o más completa que la desplegada por esos médicos que habían dado el paso de hacer un hueco al laboratorio y a la investigación en su práctica diaria de abordaje de las enfermedades infecciosas.

Aunque analizar la labor de César Chicote, director del Laboratorio Municipal de Madrid durante la pandemia, requeriría mayor espacio, destacaré las cuestiones fundamentales de su actuación con motivo de la crisis sanitaria, que reflejarán claramente cómo él era un buen exponente de esas nuevas actividades que J. P. Franco consideraba claves para mostrar a la sociedad la gran cultura científica que poseía la clase farmacéutica, totalmente comparable a la de la clase médica. Chicote aprovechó los instrumentos que le brindaba el laboratorio que dirigía para entregarse a esa loca carrera investigadora, que tenía como objetivo el aislamiento del germen responsable de la gripe, para estar en condiciones de preparar una vacuna y un suero específicos. Las dificultades que encontró para fijar la etiología no le impidieron el desarrollo de una vacuna, que tuvo a punto cuando ya estaba mediado el segundo brote de la pandemia y llegó a aplicarla, comenzando por su familia y el personal de su laboratorio. Es importante destacar cómo este farmacéutico siguió claramente la estrategia propuesta por J.P. Franco, ya que no se conformó con desplegar silenciosamente su labor dentro del laboratorio, sino que la publicitó ampliamente durante el segundo brote mediante su participación en los debates de la Real Academia Nacional de Medicina y la acción divulgadora desarrollada a través de la prensa diaria. ${ }^{55}$ Sin duda, estas importantes tareas fueron posibles no sólo por su condición de científico experto, sino también por la autoridad que emanaba del cargo que desempeñaba al frente del laboratorio de la capital de España, con el peso que estas instituciones alcanzaron durante la pandemia.

Llama la atención el protagonismo que logró durante los debates celebrados en la Real Academia Nacional de Medicina en las sesiones que esta institución dedicó durante el segundo brote, coincidiendo con los momentos de mayor gravedad. Chicote no sólo defendió sus posiciones científicas respecto del agente etiológico de la gripe, los medios para prevenirla o tratarla, sino que fue éste el foro elegido para presentar su vacuna al inicio de noviembre de $1918 .^{56}$ Es muy significativa la estrategia que utilizó para ganarse la confianza de los médicos con una vacuna que, en el mejor de los casos, podía tener alguna utilidad

54 Uno de estos farmacéuticos fue Herrero de la Orden, representante de Farmacia dentro de la Asamblea de Subdelegados de Sanidad, que participó en el debate sobre cuál era el agente específico de la gripe, optando por defender que sería una asociación microbiana (bacilo de Pfeiffer, Micrococcus catarhalis y neumococo), dados los resultados que ofrecían las investigaciones de laboratorio. Sesión científica extraordinaria del Hospital del Niño Jesús. Revista de Medicina y Cirugía Prácticas, v. 1532, p. 239-245, 28 noviembre 1918. p. 245.

55 De hecho, en cuanto tuvo a punto la vacuna y comenzó su aplicación, reportó esta información en algunos de los principales diarios de tirada nacional, como se puede ver en: Informe del Señor Chicote. ABC, p. 15, 28 octubre 1918.

56 Sesión del 9 de noviembre. Anales de la Real Academia de Madrid, v. 38, p. 435-437, 1918. Sesión del 16 de noviembre. Anales de la Real Academia de Madrid, v. 38, p. 478-479, 1918. 
contra las complicaciones bacterianas de la gripe, pero no específica contra dicha enfermedad porque su laboratorio tampoco había logrado aislar su agente específico. Optó por buscar la colaboración del sector médico al que ofreció gratuitamente su vacuna. Esta generosidad le reportó importantes beneficios, ya que no solo le permitió ganarse la confianza de ciertos médicos, sino también conseguir algunos voluntarios - como Gregorio Marañón - dispuestos a aplicar y ensayar su vacuna y, por tanto, a generar una información científica muy valiosa para Chicote. Esta sencilla maniobra le podía reportar igualmente un mayor prestigio social y unos ingresos económicos destacables, si se elegía su vacuna, en vez de cualquiera de las otras tres que estuvieron también disponibles y que fueron preparadas por médicos. ${ }^{57}$ Ahora bien, en el contexto en que se produjo, podemos pensar que uno de sus principales objetivos era conseguir situar a los farmacéuticos en un lugar privilegiado en ese nuevo campo científico-sanitario que ganaba protagonismo, aunque él manifestara que no le animaba "ningún estímulo de amor propio ni de interés profesional", sino únicamente proporcionar un instrumento útil contra la gripe..$^{58}$

El ejemplo de César Chicote ha puesto de relieve el recorrido que algunos farmacéuticos decidieron seguir para presentarse ante la sociedad como científicos expertos en los temas de Salud Pública al mismo o superior nivel que los médicos, como fue recogido claramente en la Asamblea extraordinaria de la Unión Farmacéutica Nacional celebrada el 19 de mayo de 1919, una vez que había finalizado el tercer brote de la pandemia de gripe y, como hemos indicado, cuando una parte de la clase médica seguía luchando por sus derechos y por aprobar una ley de profilaxis pública de enfermedades infecciosas como vía para lograr una modernización científico-sanitaria y dar respuesta también a las desigualdades sociales presentes en España. En este sentido es importante indicar que en dicha Asamblea, entre otras cosas, se aprobó como objetivos para el colectivo farmacéutico conseguir no sólo una asimilación con la clase médica en la Sanidad Civil, sino también ser precisamente los profesionales de la Farmacia quienes tuvieran prioridad "para el desempeño de las plazas técnicas de los Laboratorios químicos e Institutos de Higiene". ${ }^{59}$ Estas peticiones, presentadas con más fuerza en ese momento, no eran totalmente novedosas,${ }^{60}$ pero sí se beneficiaban de esa situación de mayor receptividad, que la pandemia había brindado, y de las oportunidades que la crisis sanitaria les había proporcionado para mostrar su capacitación y competencia científica frente a los médicos. Fue por eso por lo que se opusieron a ser excluidos de los nuevos laboratorios que

57 PORRAS-GALLO, op. cit., 2008, p. 276-287.

58 Sesión del 9 de noviembre. Anales de la Real Academia de Madrid, v. 38, p. 435-437, 1918.

59 Relación de los acuerdos adoptados en la Asamblea extraordinaria de la Unión Farmacéutica Nacional. La Farmacia Española, v. 17, p. 260, 10 junio 1919.

60 De hecho, reivindicaciones similares habían sido una de las razones que había dificultado la creación y materialización práctica de instituciones sanitarias, anteriores al Instituto de Higiene Alfonso XIII. PORRASGALLO, María-Isabel. Antecedentes y creación del Instituto de Sueroterapia, Vacunación y Barteriología de Alfonso XIII. Dynamis, v. 18, p. 81-106, 1998; PORRAS-GALLO, María-Isabel. Instituto Nacional de Higiene de Alfonso XIII: origen, creación y labor desempeñada. In: CARRASCOSA, Alfonso V.; BÁGUENA CERVELLERA, María José. El desarrollo de la microbiología en España, v. 1. Madrid: Fundación Ramón Areces, 2019. p. 69-103. 
los médicos crearon desde el segundo brote de la pandemia y, sobre todo, tras su finalización. Se postulaban como los profesionales idóneos para ocuparse de ellos y fabricar sueros y vacunas, y se mostraban en contra del monopolio que los médicos empezaron a establecer o de que éstos les asignaran un papel secundario en dichos laboratorios. ${ }^{61}$ Lo que estaba en juego "era una delimitación de territorios y de cotas de poder entre médicos y farmacéuticos en cuestiones de Salud Pública", a cuyo reparto como se indicará en el siguiente apartado también aspiraban los veterinarios. ${ }^{62}$

Lo que acabamos de exponer ilustra bien las expectativas que la clase farmacéutica tenía ante las iniciativas legislativas canalizadas por los médicos con el objetivo de lograr la deseada reforma sanitaria del país y su modernización científica. Es por eso por lo que no nos debe extrañar que se mostraran contrarios a apoyar los proyectos de ley que se fueron presentando en el Congreso de los Diputados, y criticaran que el ministro de la Gobernación no hubiera contado con ellos para diseñar un plan completo de reformas sanitarias, ${ }^{63}$ que tampoco prosperó.

\section{El trabajo de los veterinarios ante la pandemia de gripe de 1918- 1919: una oportunidad para su dignificación profesional}

AL IGUAL QUE PASABA con los farmacéuticos, una parte de los veterinarios estaba tratando de hacerse un hueco en las nuevas actividades ligadas a la implantación del enfoque bacteriológico en la Salud Pública con anterioridad a la pandemia de gripe de 1918-1919, pero esta crisis sanitaria les brindó una nueva oportunidad de transformar su actividad profesional, algo muy necesario por la pérdida de una parte importante de su cometido al priorizarse el vehículo de motor frente al caballo para el transporte de personas y mercancías. ${ }^{64}$ Sin embargo, el acceso real a una práctica veterinaria que incorporara la Bacteriología y les permitiera participar en los problemas de Salud Pública con participación animal no resultaba fácil, ni siquiera a partir de la incorporación de dicha disciplina en el plan de estudios de Veterinaria en 1912 y del debate suscitado sobre el valor de la introducción del laboratorio para la regeneración profesional de los veterinarios. ${ }^{65}$ La razón fundamental de ello fue el dominio ejercido por la profesión médica sobre la Microbiología, la Higiene y la Salud Pública desde sus inicios, frente a los farmacéuticos y los veterinarios, que fue una de las razones para que no prosperaran las iniciativas para aprobar una nueva ley de Sanidad desde finales del siglo XIX y durante los

61 FRANCO, J. P., ¿Rectificación?... No satisface. La Farmacia Española, v. 31, p. 484-486, 1 noviembre 1919, p. 486.

62 PORRAS-GALLO, op. cit., 2009.

63 SIBONI, Luis. ¿Reformas sanitarias o reparto del presupuesto sanitario? La Farmacia Moderna, n. 18, p. $217-$ 219, 25 de septiembre de 1919; SIBONI, Luis. El último plagio de la temporada. La Farmacia Moderna, v. 20, p. 245-246, 25 octubre 1919.

64 GUTIÉRREZ GARCÍA, José Manuel. El impacto del laboratorio en la renovación de la veterinaria española: el caso Joaquim Ravetllat i Estech (1871-1923). Medicina e Historia, v. 4 (cuarta época), p. 1-15, 2007. p. 5.

65 Ibidem. 
primeros años del Siglo $\mathrm{XX},{ }^{66}$ y que también permiten explicar el escaso desarrollo y éxito de las instituciones de higiene con anterioridad a la creación del Instituto de Higiene Alfonso XIII en 1899. Esta última iniciativa salió adelante, entre otras razones, por haber contado no sólo con los médicos, sino también con algún farmacéutico y veterinario, aunque bajo la dirección del médico Santiago Ramón y Cajal. ${ }^{67}$

Sin embargo, esta acción inclusiva no significó un cambio real de actitud y, al igual que en Gran Bretaña y a diferencia de Alemania y Francia, los médicos siguieron siendo considerados los verdaderos expertos para opinar sobre las enfermedades infecciosas de los animales, pese a que una parte de los veterinarios poseía ya esa formación específica y estaba llevando a cabo investigaciones bacteriológicas sobre las principales zoonosis. ${ }^{68}$ Tampoco ayudaba a cambiar el reconocimiento social de los veterinarios para esos temas, que la parte mayoritaria de la clase veterinaria y, sobre todo, sus líderes consideraran prioritario conseguir dignidad y autonomía profesional para mejorar la posición del colectivo veterinario e imponerse a la clase médica en los temas de Higiene y Salud Pública de los animales. Esto se reflejó en el contenido de las revistas científico-profesionales revisadas (La Semana Veterinaria, Revista de Higiene y Sanidad Veterinaria, Revista de Higiene y Sanidad pecuarias, Revista Veterinaria de España y La Veterinaria Española) durante los años de la pandemia, que dieron escasa cabida al trabajo realizado por esos veterinarios que valoraban el papel del laboratorio en el estudio de las enfermedades infecciosas animales y más allá de ellos y que, como pasó con una porción de los farmacéuticos, buscaban participar como expertos en los mismos foros que los médicos.

Sin embargo, el trabajo científico que realizaron algunos de estos veterinarios fue muy relevante $y$, durante el segundo brote, enriqueció el debate sobre las características de la pandemia de 1918-1919 en foros mayoritariamente médicos, como la Real Academia Nacional de Medicina. De hecho, en su sesión del 12 de noviembre de 1918, Dalmacio García Izcara planteó que era un "virus filtrable" el agente etiológico de la gripe, en vez del bacilo de Pfeiffer o alguna de las otras bacterias que se aislaban. ${ }^{69}$ Esta hipótesis etiológica fue una de las más rompedoras desde el punto de vista científico y, como pusieron de relieve otras intervenciones de García Izcara en la citada Academia, su propuesta se había beneficiado de su experiencia investigadora y observadora como veterinario, que le proporcionó un conocimiento de la presencia del problema de salud pública responsable de la crisis sanitaria en los caballos. ${ }^{70}$

66 Dalmacio García Izcara, catedrático en la Escuela de Veterinaria de Madrid, fue uno de los que denunció la postergación de los veterinarios en los temas de Higiene Pública y el protagonismo otorgado a los médicos en el proyecto de ley presentado en 1911 para tratar de aprobar una nueva Ley de Sanidad. GARCÍA IZCARA, Dalmacio. Informe del Colegio Oficial de Veterinarios de la provincia de Madrid a la Comisión del Senado que entiende en el Proyecto de bases para una Ley de Sanidad. Revista de Higiene y Sanidad Veterinaria, n. 1, p. 87-97, 1911.

67 PORRAS-GALLO, op. cit., 1998; PORRAS-GALLO, op. cit., 2019.

68 GUTIÉRREZ GARCIA, José Manuel. El impacto del laboratorio en la renovación de la veterinaria española: el caso Joaquim Ravetllat i Estech (1871-1923). Medicina e Historia, n. 4 (cuarta época), p. 1-15, 2017. p. 7-8.

69 PORRAS-GALLO, op. cit., 1994a, p. 324. PORRAS-GALLO, op. cit., 2008.

70 PORRAS-GALLO, op. cit., 1994a, p. 324. 
Es interesante recordar que este veterinario formaba parte del Instituto de Higiene Alfonso XIII, centro que fue clave en el desarrollo de la bacteriología y virología en España. ${ }^{71}$ Otra contribución de interés fue la de Ramón Turró, director del Laboratorio Municipal de Barcelona, institución que tuvo un gran protagonismo en el estudio y gestión de la pandemia de 19181919, pero también posteriormente en el desarrollo de la bacteriología, virología, Higiene y Salud Pública. Este otro veterinario fue igualmente defensor del "virus filtrante" como germen específico de la gripe. ${ }^{72}$ Otra de las opciones propuesta fue considerar que la etiología era "completamente desconocida", como postuló el anónimo veterinario que firmaba su artículo en la revista La Veterinaria Española, como "Un veterinario rural". ${ }^{73}$

Al igual que pasó con los médicos o los farmacéuticos, las hipótesis etiológicas del virus filtrable o un agente desconocido fueron minoritarias, siendo más frecuente el mantenimiento del papel protagonista del bacilo de Pfeiffer, solo o acompañado por otras bacterias (estreptococos y neumococos), como hizo el Profesor Sugrañes, Subdelegado del Cuerpo de Veterinarios municipales. Apoyándose en los trabajos experimentales que se habían realizado con animales, Sugrañes mantenía una posición diferente a la de García Izcara y consideraba que la gripe afectaba únicamente a los seres humanos.

Los ejemplos seleccionados hasta ahora reflejan cómo ese sector minoritario de la clase veterinaria que incorporó el laboratorio y la bacteriología en su actividad para abordar las enfermedades infecciosas, aprovechó la pandemia para estudiar el problema y mostrar su capacitación al mismo nivel que los médicos en el campo de la Salud Pública. Además, como hicieron los otros dos grupos de profesionales sanitarios de los que nos hemos ocupado, a la vez que daban muestras de su capacitación con la gripe de 1918-1919 siguieron presentando sus demandas profesionales y defendiendo la exclusividad de algunas parcelas de la Salud Pública frente a médicos y farmacéuticos, como la inspección sanitaria de los alimentos o el estudio de las zoonosis. Ahora bien, al hacerlo, insistían en que ese papel debía desempeñarlo "el profesor Veterinario moderno", ese que era "un facultativo capacitado", porque su formación había incluido "elementos modernos para especializarse en conocimientos de Biología, Microbiología, Higiene, Inspección substancias alimenticias, etc.", que le permitían realizar sus funciones adecuadamente. ${ }^{74}$ No obstante, los veterinarios y sus organizaciones solicitaron mejoras en su formación y el paso de Escuela Veterinaria a Facultad de Veterinaria. Con ello buscaban una mayor capacitación de los veterinarios que les posibilitara librarse del intrusismo médico en los ámbitos de la Salud e Higiene Públicas que consideraban propios. ${ }^{75}$

71 PORRAS-GALLO, op. cit., 1998; PORRAS-GALLO, op. cit., 2019.

72 RODRÍGUEZ OCAÑA, Esteban. La grip a Barcelona: un greu problema esporàdic de salud publica. Epidèmies de 1889-90 i 1918-19. In: Cent anys de Salut Publica a Barcelona. Barcelona: Institut Municipal de la Salut, 1991. p. 131-156.

73 UN VETERINARIO RURAL. Profilaxis de las enfermedades infecciosas y parasitarias (I). La Veterinaria Española, v. 2198, p. 481-486, 31 diciembre 1918.

74 Ibidem, p. 481.

75 GUERRA, Ángel. I. Numerosos telegramas. II El proyecto de ley de Epidemias. III. Próximas reformas docentes 
Aunque no todas sus demandas fueran atendidas, fue reconocido el importante papel que había desempeñado la pandemia de gripe de 1918-1919 para poder exhibir su preparación científica y hacerse un hueco en el ámbito de la Salud Pública y para otorgarle nueva visibilidad a sus reivindicaciones profesionales, ${ }^{76}$ que permitió la obtención de algún fruto, como la aprobación del reglamento de Mataderos, coincidiendo con su campaña reivindicativa. ${ }^{77}$

Si los farmacéuticos habían tenido como referente a la clase médica, los veterinarios se inspiraron en parte en los farmacéuticos para plantear un modelo organizativo profesional similar, como la creación de "La Federación Nacional Veterinaria", buscando la unidad de la clase veterinaria como una vía para oponerse al intrusismo médico y lograr mejor instalación social en el ámbito de la Salud Pública. ${ }^{78}$ También fue considerado dar un paso más y promover el establecimiento de una "Federación de las tres clases sanitarias", fijando unas condiciones y unos requisitos. Algunos entendían que este asociacionismo podía permitir la concordia entre las tres profesiones, la delimitación de los ámbitos de actuación de cada una de ellas, sobre todo en el mundo rural, y reforzar sus posiciones sociales. ${ }^{79}$

\section{Algunas reflexiones finales}

A LO LARGO DE LAS PÁGINAS precedentes se ha puesto de relieve cómo la pandemia de gripe de 1918-1919 transformó la actividad diaria de los médicos cuantitativa y cualitativamente, debiendo compatibilizar el aumento de su dedicación a la labor clínica con el desarrollo de labores investigadoras de laboratorio, que buscaba un abordaje más certero y resolutivo de la crisis sanitaria presente. Sin embargo, este nuevo trabajo desplegado no alcanzó el rendimiento esperado para controlar y minimizar el impacto de la pandemia, propiciando una mirada más plural para explicar su gravedad y, en consonancia con ello, la consideración de elementos de protección social y de la higiene laboral y social como instrumentos apropiados de profilaxis de las enfermedades infecciosas y de mejora socio-económica y modernización científico-sanitaria. A pesar del fracaso de la Medicina bacteriológica contra la gripe de 1918-1919, esta crisis ayudó a consagrar el papel del laboratorio bacteriológico

en Veterinaria. La Veterinaria Española, v. 2182, p. 225-228, 31 mayo 1918; GUERRA, Ángel. I. Reformas docentes aprobadas. II. Los herradores de tres años. III Petición incomprensible. La Veterinaria Española, v. 2184, p. 257-260, 20 junio 1918; SALDAÑA y SICILIA, G. Peligros de una proyectada reforma. La Veterinaria Española, v. 2191, p. 370-374, 15 septiembre 1918; FERNÁNDEZ, Aproniano. Maremagnum y confusión. La Veterinaria Española, v. 2192, p. 386-389, 30 septiembre 1918; MORELLÓ, José. Los seudo-veterinarios. La Veterinaria Española, v. 2192, p. 385-386, 30 septiembre 1918; GUERRA, Ángel. Justificación de una retirada. La Veterinaria Española, v. 2189, p. 338-345, p. 341, 15 agosto 1918.

76 UN VETERINARIO RURAL. Profilaxis de las enfermedades infecciosas y parasitarias (I). La Veterinaria Española, v. 2198, p. 481-486, 31 diciembre 1918.

77 Ángel Guerra, director de La Veterinaria Española, lo indicaba en la nota 1 del artículo: Un Veterinario Rural, op. cit., 1918, p. 481.

78 FERNÁNDEZ GALLEGO, Luis. Extracto de lo acordado por los Veterinarios del distrito de Belchite (Zaragoza), en la reunión celebrada por los mismos el día 14 de agosto, p. 338; GUERRA, Ángel. Justificación de una retirada. La Veterinaria Española, v. 2189, p. 338-345, 15 agosto 1918. p. 341.

79 VIDAL, Gedeón. Bases para una Federación profesional. La Veterinaria española, v. 2182, p. 194-196, 10 mayo 1918. Es interesante destacar que en este artículo se exponían las condiciones y requisitos para llevar a cabo la Federación de las tres clases sanitarias. 
en la lucha contra las enfermedades infecciosas y se convirtió en una gran oportunidad para volver a solicitar las viejas demandas profesionales de la clase médica y trabajar en su reorganización profesional.

Una parte de los farmacéuticos y veterinarios consideraron la pandemia como una oportunidad para avanzar en la introducción de la actividad investigadora bacteriológica en sus actuaciones contra las enfermedades infecciosas y desarrollar un papel como expertos a un nivel similar al de los médicos, con el objetivo de delimitar los ámbitos de actuación de cada una de las tres profesiones sanitarias en el campo de la Salud pública. Siguiendo los farmacéuticos el modelo de los médicos y los veterinarios el de los farmacéuticos, combinaron sus labores científicas de expertos con la intensificación de sus demandas profesionales, logrando únicamente algunas de ellas que implicaron una transformación parcial y, generalmente, menor de lo esperado, de su actividad laboral tras la pandemia.

Recebido em: 06/07/2020

Aprovado em: 04/08/2020 